In this study of a homogenous population of transplant recipients who had received transfusions, treated with conventional immunosuppressive drugs, continuous ambulatory peritoneal dialysis was not found to be a risk factor for the survival of patients or grafts, and its continued use in the preparation of patients with end stage renal failure for transplantation is recommended.

We thank the medical and nursing staff of the renal units in the Northern region and Mrs R Grieveson, Mrs E Robson, and Mrs C Hudson for secretarial work.

\section{References}

1 Kolff WJ, Berk HTJ, Welle M, van Ley AJW, van Dijk EC, van Noordwijk J. The artificial kidney : a dialyser with a great area. Acta Med Scand 1944;117:121. Oreopoulos DG, Khanna R, Williams P, Vas SI. Continuous ambulatory peritoneal dialysis-1981. Nephron 1982;30:293-303.

3 Wing AJ, Broyer M, Brunner FP, Brynger $\mathrm{H}$, et al. Combined report on regular dialysis and transplantation in Europe. Proc Eur Dial Transplant Assoc 1983; 20:5-78. 4 Hume DM, Mervill JP, Miller BF, Thorn GW. Experiences with renal trans-

5 Opelz G, Terasaki PI. Dominant effect of transfusion on kidney graft survival.

6 Guillou PJ, Will EJ, Davison AM, Giles GR. CAPD-a risk factor in clinical renal transplantation? Br ₹ Surg 1984;71:878-80

7 Dewar PJ, Wilkinson R, Elliott RW, et al. Superiority of B locus matching over other HLA matching in renal graft survival. Br Med $\mathcal{F}_{1982} ; 284: 779-82$.

8 Dewar PJ, Murray S. Lymphocytotoxic antibody detection and cross matching in renal transplantation. Transplantation 1976;21:387-90.

Striker GE, Tenckhoff AM. A transcutaneous prosthesis for prolonged access to the peritoneal cavity. Surgery 1971;69:70-4. 0 Francis DMA, Donnelly PK, Veitch PS, et al. Surgical aspects of continuous
peritoneal dialysis-3 years' experience. Br $\mathcal{F}$ Surg $1984 ; 71: 225-9$. 11 Ramos JM, Gokal R, Siamopolous $\mathrm{K}$, Ward $\mathrm{MK}$, Wilkinson $\mathrm{R}$, Kerr $\mathrm{DNS}$ ;52:165-86.

12 Lee E, Desu M. A computer program for comparing $\mathrm{K}$ samples with right 3 Cox DR. Regression models and life tables. Ұournal of the Royal Statistical Society, Series B 1972;34:187-220.

14 Sanfilippo F, Vaughn WK, Specs EK, Light JA, le For WM. Benefits of HLA-A and HLA-B matching on graft survival and patient outcome after cadavericdonor renal transplantation. $N$ Engl f Med 1984;311:358-64.

15 Donnelly PK, Henderson R, Lennard TWJ, Proud G, Taylor RMR. Specific and non-specific immunoregulatory factors and renal allograft survivalsingle centre 5 year experience. Transplant Proc (in press).

End demands. Health Trends 1984;16:1-3.

, Hosking CS, Atkins RC. The effect of mainten ance haemodialysis on lymphocyte function I: haemodialysis. Clin Exp Immunol 1978;33:95-101.

18 Collart F, Tielemans C, Dratwa M, Schandene L, Wybran J, Dupont E. Haemodialysis, continuous ambulatory peritoneal dialysis and cellular immunity. Proc Eur Dial Transplant Assoc 1983;20:190-

19 Valderradano F, Anaya F, Perez-Garcia R, Olivas E, Vasconez F, Jofre R. Transfusion-induced anergy: skin test as an index for pretransplant transfusions. $1983 ; 20: 338-48$.

20 Langhoff $E$, Ladefoged J. Improved lymphocyte transformation in vitro of patients on continuous ambulatory peritoneal dialysis. Proc Eur Dial Transplan Assoc $1983 \cdot 20 \cdot 230-5$.

21 Giagrande A, Canta P, Limido A, de Francero D, Malacrida T. Continuous ambulatory peritoneal dialysis and cellular immunity. Proc Eur Dial Transplant Assoc 1982;19:372-9.

22 Gokal R, Ramos JM, Veitch PS, et al. Renal transplantation in patients on continuous ambulatory peritoneal dialysis. Proc Eur Dial Transplant Assoc

$1981 ; 18: 222-7$.
23 Leblr HW, Spiegelhalter R, Ulm A, Goubeaud G, Rawer P. Influence of middle molecules on the anemia of uremic patients. Artif Organs 1978;2:378-81.

24 Salahudeen AK, Hawkins T, Keavey PM, Wilkinson R. Is anaemia during continuous ambulatory peritoneal dialysis better than during haemodialysis

25 Opelz G, Mick rect 1981 XIII :136-41.

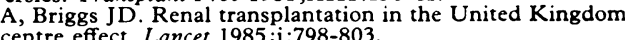
Tancet $1985 ; \mathrm{i}: 798-803$.

(Accepted 10 fuly 1985)

\title{
Renal transplantation in patients treated with haemodialysis and short term and long term continuous ambulatory peritoneal dialysis
}

\author{
JOAO B EVANGELISTA JR, DAVID BENNETT-JONES, J STEWART CAMERON, CHISHOLM OGG, \\ D GWYN WILLIAMS, DAVID H TAUBE, GUY NEILD, CHRIS RUDGE
}

\begin{abstract}
Forty two adult patients who had been treated with continuous ambulatory peritoneal dialysis for one to 142 weeks (mean (SD) 38 (36)) received a total of 44 allografted kidneys. Twenty one had been treated with continuous ambulatory peritoneal dialysis for less than 26 weeks (mean $11(8)$ ) and the other 21 for longer than 26 weeks (mean $64(35)$ ). These two groups were compared with 55 patients who had been treated with haemodialysis and received a total of 63 grafts.

In the group of patients treated with continuous ambulatory peritoneal dialysis azathioprine and low dose prednisolone were used as the immunosuppressive regimen for 20 transplantations in 18 patients, and 24 patients receiving 24 grafts were treated with cyclosporin
\end{abstract}

Renal Unit, Guy's Hospital, London SE1 9RT JOAO B EVANGELISTA Jr, MD, clinical fellow DAVID BENNETT-JONES, BA, MRCP, research registrar J STEWART CAMERON, MD, FRCP, professor of renal medicine CHISHOLM OGG, MD, FRCP, consultant renal physician D GWYN WILLIAMS, MD, FRCP, consultant renal physician DAVID H TAUBE, MB, MRCP, senior registrar GUY NEILD, MB, MRCP, lecturer in medicine CHRIS RUDGE, BSC, FRCS, consultant surgeon

Correspondence to: Dr Ogg.
A and low dose prednisolone. In the group of patients treated with haemodialysis 38 patients receiving 43 grafts were treated with azathioprine and low dose prednisolone, and 20 patients receiving 20 grafts were treated with cyclosporin $A$ and low dose prednisolone.

Actuarial survival of patients and grafts at two years was $95 \%$ and $72 \%$, respectively, in the continuous ambulatory peritoneal dialysis group compared with $89 \%$ and $58 \%$, respectively, in the haemodialysis group. No difference was found in graft survival between short term treatment with continuous ambulatory peritoneal dialysis $(72 \%$ graft survival) and long term treatment $(65 \%$ graft survival).

In conclusion, continuous ambulatory peritoneal dialysis is suitable treatment for patients awaiting renal transplantation.

\section{Introduction}

An increasing number of patients with end stage renal failure throughout the world have been treated with continuous ambulatory peritoneal dialysis since its introduction in 1976. The 1984 report from the European Dialysis and Transplant Association showed that 5228 patients in Europe had been treated with continuous ambulatory peritoneal dialysis up to December 1983. The United Kingdom accounted for almost a third of this total. ${ }^{1}$ The risk of septic complications secondary to the presence of an 
indwelling Tenckhoff catheter has been considered to be a relative contraindication to this mode of dialysis treatment in patients awaiting kidney transplantation. Since 1980 we have used continuous ambulatory peritoneal dialysis as a first choice treatment for patients with end stage renal failure. We report the results of renal transplantation in 42 patients treated with continuous ambulatory peritoneal dialysis, 29 of whom had received continuous ambulatory peritoneal dialysis as first choice of treatment.

\section{Patients and methods}

From November 1980 to May 1984 a total of 175 consecutive renal transplant operations were performed in 166 adult patients with end stage renal failure and a total of 120 patients were treated with continuous ambulatory peritoneal dialysis at Guy's Hospital. We compared all 42 patients treated with continuous ambulatory peritoneal dialysis up to renal transplantation, only two of whom received allografts before January 1982, with the 55 patients who were treated exclusively with haemodialysis and received transplants between January 1982 and May 1984. Patients who had previously been treated with continuous ambulatory peritoneal dialysis but who had been transferred to haemodialysis before transplantation were not included in this study.

Before transplantation patients receiving continuous ambulatory peritoneal dialysis were treated with a standard method using an indwelling Tenckhoff catheter for one to 142 weeks (mean (SD) 38 (36)). Twenty one patients were treated for less than 26 weeks (mean 11 (8)) (short term group) and 21 were treated with continuous ambulatory peritoneal dialysis for longer than 26 weeks (mean 64 (35)) (long term group). Infection at the exit site of the catheter occurred in nine patients, and 60 episodes of peritonitis occurred in 27 patients. Staphylococcus epidermis was the most common causative organism (in $32^{\circ}$ of cases). Thirteen out of 15 patients who did not experience peritonitis had been treated with continuous ambulatory peritoneal dialysis for less than 26 weeks.

Although there was no deliberate selection of patients to receive continuous ambulatory peritoneal dialysis for short or long term periods, 17 out of 42 patients were given priority for a renal transplant on account of problems related to dialysis, including peritonitis, technical difficulties, and depression.

All patients had received at least five preoperative blood transfusions. Before July 1983 all patients received azathioprine and low dose prednisolone for immunosuppression"; since then cyclosporin A and low dose prednisolone have been used.

An initial dose of cyclosporin A ( $7 \mathrm{mg} / \mathrm{kg}$ orally) was given preoperatively and then a daily oral dose of $14 \mathrm{mg} / \mathrm{kg}$ body weight, reducing by $2 \mathrm{mg} / \mathrm{kg}$ body weight by the 14th day and every 30 days after transplantation. By the end of three months the maintenance dose was $6 \mathrm{mg} / \mathrm{kg}$ body weight. This schedule was altered if there was any clinical or histopathological evidence of toxicity. Prednisolone was given at an initial daily dose of $15 \mathrm{mg} / \mathrm{m}^{2}$ body surface area, reducing to $7.5 \mathrm{mg} / \mathrm{m}^{2}$ body surface area after one year. Episodes of rejection were treated with $1 \mathrm{~g}$ methylprednisolone intravenously for three consecutive days. Antilymphocyte immunoglobulin was used to treat severe rejection that was unresponsive to treatment with steroids in 11 patients.

The clinical state of patients and plasma concentration of creatinine after transplantation were recorded at the most recent visit to the clinic, with a minimum follow up of three months and a maximum of three years and seven months. Actuarial survival of patients and grafts was calculated according to life table analysis with comparison by the log rank test. ${ }^{3}$ The Wilcoxon rank sum test was used to compare the creatinine concentrations after transplantation.

\section{Results}

Table I shows patients' age, sex, source of donor, number who received first and subsequent transplants, and mean plasma creatinine concentration before transplantation. Pyelonephritis and diabetes were more common causes of renal failure in the continuous ambulatory peritoneal dialysis group than the haemodialysis group $(18 \% v$ $9 \%$ and $10 \%, 05 \%$, respectively), whereas polycystic kidney disease was more common in the haemodialysis group than the continuous ambulatory peritoneal dialysis group $(11 \% v 3 \%)$. The proportion of patients who received cyclosporin A was higher in the continuous ambulatory peritoneal dialysis group than the haemodialysis group.
TABLE I-Data on 97 recipients of renal allografts

\begin{tabular}{|c|c|c|}
\hline & \multicolumn{2}{|c|}{ Treatment } \\
\hline & $\begin{array}{l}\text { Continuous ambulatory } \\
\text { peritoneal dialysis }\end{array}$ & Haemodialysis \\
\hline $\begin{array}{l}\text { No of grafts/patients } \\
\text { Age range (mean (SD)) (years) } \\
\text { Men :women } \\
\text { Living donor:cadaver } \\
\text { No receiving first transplant } \\
\text { No receiving second or third }\end{array}$ & $\begin{array}{c}44 / 42^{*} \\
15-72(44(17)) \\
34: 8 \\
2: 42 \\
34\end{array}$ & $\begin{array}{c}63 / 55 \dagger \\
17-62(40(15)) \\
35: 20 \\
4: 59 \\
47\end{array}$ \\
\hline transplant & 10 & 16 \\
\hline $\begin{array}{l}\text { Azathioprine/cyclosporin A } \\
\text { treatment }\end{array}$ & $20 / 24$ & $43 / 20$ \\
\hline $\begin{array}{l}\text { Mean (SD) serum creatinine before } \\
\text { transplantation }(\mu \mathrm{mol} / \mathrm{l})\end{array}$ & $1013(300)$ & $1040(220)$ \\
\hline
\end{tabular}

*Three patients had been desensitised.

†Two patients had been desensitised.

Conversion: SI to traditional units-Serum creatinine: $1 \mu \mathrm{mol} / 1 \approx 0.01 \mathrm{mg} / 100 \mathrm{ml}$.

Three patients in the continuous ambulatory peritoneal dialysis group and two in the haemodialysis group had received cyclophosphamide, prednisolone, and plasma exchange during the two months before transplantation to reduce high titres of antibodies against HLA antigens. ${ }^{4}$

No difference was seen between patients who had received short term and long term treatment with continuous ambulatory peritoneal dialysis with respect to patients' age, sex, source of donor, immunosuppressive regimen, and serum creatinine concentration after transplantation. There were, however, slightly more first transplants given to patients in the short term treatment subgroup (19/21) compared with the long term subgroup $(16 / 23)$.

Data analysed up to September 1984 showed that 40 of 42 patients from the continuous ambulatory peritoneal dialysis group and 50 of 55 patients from the haemodialysis group had survived. One patient from the continuous ambulatory peritoneal dialysis group and two from the haemodialysis group died with a functioning graft. These were regarded as lost to follow up in the analysis of graft survival. In the continious ambulatory peritoneal dialysis group 30 patients had a functioning graft, five were transferred to treatment with haemodialysis after loss of graft, and five received continuous ambulatory peritoneal dialysis again. In the haemodialysis group 36 had a functioning graft, five were transferred to continuous ambulatory peritoneal dialysis, and nine received haemodialysis again after the graft had failed.

\section{DEATHS}

Two patients from the continuous ambulatory peritoneal dialysis group died during the first two months after transplantation from septicaemia and pulmonary embolism, respectively. The patient who died from septicaemia, aged 49 years, had been immunosuppressed for the two months before transplantation for densensitisation ${ }^{4}$; the other patient, aged 61 years, was known before transplantation to suffer from ischaemic heart disease.

In the haemodialysis group five patients aged 40-62 (mean 55.8 years) died two months to one year after transplantation. Two patients died from septicaemia, one secondary to osteomyelitis and the other secondary to interstitial pneumonitis, one year and five months after receiving their transplant, respectively. Two patients died with a functioning graft, one from myocardial infarction and the other from uncontrolled pulmonary haemorrhage after lung biopsy; both occurred in the second month after transplantation. The fifth patient died with widespread renal cell carcinomatosis arising from his remaining polycystic kidneys, 10 months after losing his graft. Cumulative survival of patients at two years was not significantly different $(95 \%$ in the continuous ambulatory peritoneal dialysis group and $89 \%$ in the haemodialysis group).

\section{GRAFT LOSSES AND REJECTION EPISODES}

In the continuous ambulatory peritoneal dialysis group 14 graft losses were recorded, but none related to previous treatment with continuous ambulatory peritoneal dialysis. Acute rejection was responsible for half of the losses. Two grafts were lost as a result of chronic rejection three and five months after transplantation, and one patient died with a functioning graft. Oxalosis and mesangiocapillary glomerulonephritis recurred in two patients, causing graft failure one month and one year after transplantation. Two patients lost their grafts 
after immunosuppression had been withdrawn because of severe wound infection in a young woman with diabetes and herpes zoster in a 62 year old recipient with amyloidosis.

In the haemodialysis group 27 graft losses were recorded. Acute rejection was responsible for 11 failures and chronic rejection for eight. Two patients died from myocardial infarction and pulmonary haemorrhage with a functioning kidney. Two grafts were lost because of irreversible venous thrombosis. Infection leading to the withdrawal of immunosuppression caused three losses. Antirejection treatment was used 88 times (two times/patient) in the continuous ambulatory peritoneal dialysis group and 141 times $(2.6$ times/patient) in the haemodialysis group.

\section{GRAFT SURVIVAL}

The graft survival in the continuous ambulatory peritoneal dialysis group at one and two years was $72 \%$ compared with $64 \%$ and $58 \%$ in the haemodialysis group $\left(\chi^{2}=0.485, \mathrm{df}=1, \mathrm{p}>0.4\right)$. As there was a slight imbalance in immunosuppressive regimens the figure presents the actuarial graft survival of patients receiving the same immunosuppression. In the patients treated with cyclosporin A the graft survival at one year was $77 \%$ in the continuous ambulatory peritoneal dialysis

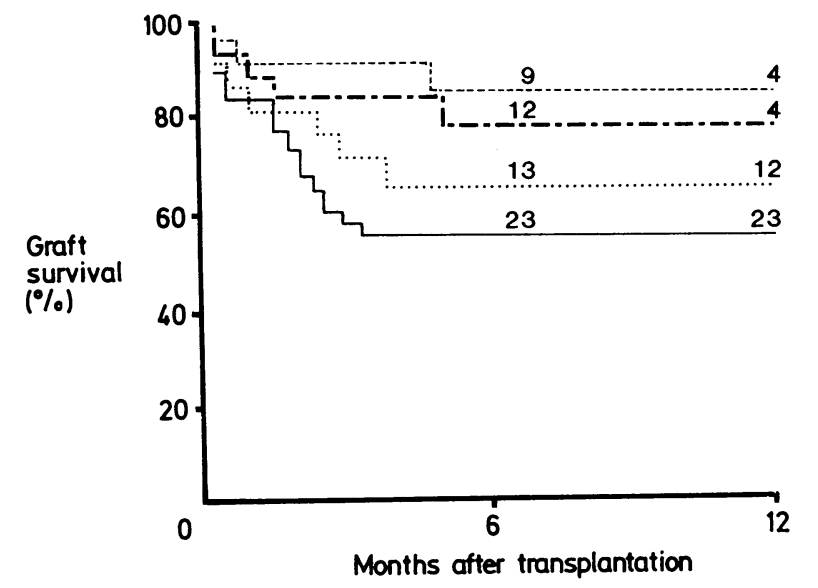

Actuarial graft survival for different subgroups. Treatment with haemodialysis + cyclosporin A $(---\longrightarrow)$; continuous ambulatory peritoneal dialysis + cyclosporin A (-.-...); continuous ambulatory peritoneal dialysis +azathioprine $(\cdots \cdots)$; haemodialysis + azathioprine (Figures at six and 12 months are numbers of patients surviving.

group, compared with $83 \%$ in the haemodialysis group. In patients treated with azathioprine graft survival in the continuous ambulatory peritoneal dialysis group was $65 \%$ and in the haemodialysis group $55 \%$. The log rank test, with stratification for the different immunosuppressive regimens, showed no significant difference between the two groups $\left(\chi^{2}=0 \cdot 25, \mathrm{df}=1, \mathrm{p}>0 \cdot 5\right)$. The actuarial graft survival was $73 \%$ in the short term treatment subgroup and $65 \%$ in the long term subgroup, at both one and two years $\left(\chi^{2}=0.59, \mathrm{df}=1, \mathrm{p}>0.4\right)$.

The serum creatinine concentration after transplantation showed no significant difference between the continuous ambulatory peritoneal dialysis group (mean (SD) $148(48) \mu \mathrm{mol} / 1(1.7(0.5) \mathrm{mg} / 100 \mathrm{ml})$ ) and the haemodialysis group (mean (SD) 148 (83) $\mu \mathrm{mol} / 1(1 \cdot 7$ $(0.9) \mathrm{mg} / 100 \mathrm{ml})$ ). In the continuous ambulatory peritoneal dialysis group patients who received cyclosporin A had a slightly higher serum creatinine concentration (mean (SD) 157 (52) $\mu \mathrm{mol} / \mathrm{l}(1 \cdot 8(0 \cdot 6) \mathrm{mg} /$ $100 \mathrm{ml})$ ) than those who received azathioprine (mean (SD) 137 (34) $\mu \mathrm{mol} / 1(1.6(0.4) \mathrm{mg} / 100 \mathrm{ml}))$, but this was not significant (Wilcoxon's rank sum test).

\section{COMPLICATIONS}

Nineteen patients in the continuous ambulatory peritoneal dialysis group required dialysis in the immediate postoperative period, four of whom were treated with continuous ambulatory peritoneal dialysis for five to 50 days. Postoperatively, one patient suffered an episode of
Staph epidermis peritonitis that was successfully managed with peritoneal lavage with antibiotics. Another problem was the occurrence of serous leaks from the catheter without clinical relevance (apart from the differential diagnosis between haematoma or cystic $c$ lymphangioma) in two patients. No peritonitis was observed in patients treated with haemodialysis after operation.

\section{TENCKHOFF CATHETER}

Infections, apart from peritonitis, occurred with similar regularity in both groups (table II). Infection of wounds was slightly more common in the continuous ambulatory peritoneal dialysis group (five episodes) than in the haemodialysis group (three episodes), but no relation to infection at the exit site of the catheter was noticed.

TABLE II-Infective complications after transplantation

\begin{tabular}{lcc}
\hline & \multicolumn{2}{c}{ Treatment } \\
\cline { 2 - 3 } Infection & $\begin{array}{c}\text { Continuous ambulatory } \\
\text { peritoneal dialysis }(\mathrm{n}=26)\end{array}$ & Haemodialysis $(\mathrm{n}=\mathbf{3 3})$ \\
\hline Chest & 6 & 8 \\
Wound & 5 & 3 \\
Urinary tract & 7 & 0 \\
Peritonitis & 1 & 9 \\
Others & 4 & 11 \\
Viral/pneumocystis & 15 & 40 \\
\hline Total & 38 & \\
\hline
\end{tabular}

The Tenckhoff catheter was taken out at the time of transplantation in 12 patients. In 23 patients it was removed from 30 to 232 days (mean (SD) 99 (58) days) postoperatively. Fifteen of these patients had the peritoneal catheter removed at the same time as cystoscopy to remove the ureteric stent.

\section{Discussion}

Over the past five years there has been a considerable increase in the number of patients given transplants after treatment with continuous ambulatory peritoneal dialysis as a result of its increased use in end stage renal failure. The probability of a patient receiving continuous ambulatory peritoneal dialysis being transferred to another treatment is about $40 \%$ at the end of the first year, though only about $7.5 \%$ of these are given transplants. ${ }^{1}$

Although continuous ambulatory peritoneal dialysis has been accepted as suitable treatment for end stage renal failure, there are anxieties about possible complications related to continuous ambulatory peritoneal dialysis after transplantation, which may $\delta$ have prevented transplants being given to patients treated with continuous ambulatory peritoneal dialysis at some renal units. 0 Rigby et al emphasised that the risk of peritonitis does not preclude transplantation. They were able to control easily three o episodes of peritonitis in three out of 23 patients given continuous $\frac{7}{0}$ ambulatory peritoneal dialysis who received 35 grafts. ${ }^{56}$ Our experience in this retrospective study is in accord with others who $N$ did not show differences between patients who had received $\underset{\omega}{N}$ continuous ambulatory peritoneal dialysis or haemodialysis. ${ }^{7}{ }^{8}$ Actuarial survival of patients at two years was $95 \%$ in the con- 0 tinuous ambulatory peritoneal dialysis group and $89 \%$ in the haemodialysis group. These figures should be considered to be $\stackrel{\text { ? }}{+}$ excellent in a group of patients with a mean age of 40 years, 0 some as old as 70 . Some patients who had failed continuous ambulatory peritoneal dialysis and subsequently changed treatment to haemodialysis were excluded from this study as they $\stackrel{\mathbb{D}}{\Omega}$ had not received transplants before the transfer of dialysis.

When graft survival was compared in the continuous ambulatory peritoneal dialysis and haemodialysis groups for each immunosuppressive regimen no significant difference was seen. Graft survival was also similar in patients who received short $\stackrel{\bar{a}}{\vec{F}}$ 
term or long term treatment with continuous ambulatory peritoneal dialysis. The small difference may be related to the number of transplant operations performed in patients who received short term treatment.

Complications after transplantation related to continuous ambulatory peritoneal dialysis were minimal. Only one episode of peritonitis was observed, which was easily treated with intraperitoneal antibiotics. Cramer et al reported the development of peritonitis after transplantation in one patient who received continuous ambulatory peritoneal dialysis who had never had an episode of peritonitis before transplantation, indicating a risk of activation of subclinical peritonitis in an immunosuppressed patient. ${ }^{9}$ This was not observed by us or others. ${ }^{610}$ Eight of our 42 patients who had had at least four episodes of peritonitis before transplantation, and who could, therefore, be considered to be patients at high risk, had no apparent peritoneal infection after transplantation.

The routine maintenance of the indwelling Tenckhoff catheter after transplantation was not a problem. It was used by choice in four of 19 patients who required dialysis in the immediate postoperative period. Those catheters that were not removed at the time of transplantation were withdrawn after a mean of three months when the graft function was stable. The operation was uneventful, and in 15 patients it was performed at the same time as removal of the ureteric stent at cystoscopy.

In conclusion, continuous ambulatory peritoneal dialysis is not an impediment to successful renal transplantation. The risk of peritonitis after transplantation should be borne in mind in patients treated with continuous ambulatory peritoneal dialysis, and even in the absence of clinical signs we would advise routine sampling of peritoneal fluid for bacteriological study.
The Tenckhoff catheter can be used to perform dialysis in those who do not have immediate graft function. Short term treatment with continuous ambulatory peritoneal dialysis is an excellent mode of treatment as a "parking place" for patients awaiting renal transplantation, which does not take up places in renal units, allows patients home in a week or two, and has minimal capital costs.

Joao B Evangelista Jr received support from the British Council during this study and David Bennett-Jones from Travenol UK. We thank all members of the renal unit staff who cared for these patients.

\section{References \\ 1 Kramer P, Broyer M, Brunner FP, et al. Combined report on regular dialysis and transplantation in Europe XiV. Proc Eur Dial Transplant Assoc 1985;21: \\ 2 Papadakis J, Brown CB, Cameron JS, et al. A prospective controlled trial of "high" versus "low" dose corticosteroid in transfused recipients of cadaver Peto R, Pike MC, Armitage P, et al. Design and analysis of randomised clinical rial requiring prolonged observations of each patient. II Analysis and examples. Br F Cancer 1977;35:1-39. \\ 4 Taube DH, Williams DG, Cameron JS, et al. Renal transplantation after removal and prevention of resynthesis of HLA antibodies. Lancet 1984 ; i:824-6. \\ Rigby RJ, Butler JL, Petrie JJB. Experience with continuous ambulatory peri- \\ toneal dialysis. Med $\mathcal{f}$ Aust $1982 ; \mathrm{i}: 331$.
6 Rigby RJ, Petrie JJ. Experience of transplantation in patients on continuous ambulatory peritoneal dialysis (CAPD). Transplantation 1984;37:533. \\ Wood C, Thomson NM, Scott DF, Holdsworth Field, Rich, and Associates (in press) \\ 8 Shapira Z, Shmueli D, Yussim A, Boner G, Haimovitz C, Servadio C. Kidney ransplantation in patients on continuous ambulatory peritoneal dialysis. Proc Eur Dial Transplant Assoc 1984;21:932-5. \\ 9 Cramer SO, Adams MB, Kauffman JRHM. Post-transplant peritonitis in a CAPD \\ 10 Patel S, Rosenthal JT, Hakala TR. Management of the peritoneal dialysis catheter after transplantation. Transplantation 1983;36:589-90.}

\title{
Process and outcome of care for patients with ovarian cancer
}

\author{
A LIBERATI, C MANGIONI, L BRATINA, G CARINELLI, S MARSONI, F PARAZZINI, \\ M REGALLO, R TALAMINI, G TOGNONI
}

\begin{abstract}
The process and outcome of care for a group of patients with ovarian cancer treated over two years in two groups of Italian general hospitals were investigated. The quality of diagnostic and therapeutic measures did not substantially differ in specialised and non-specialised centres when selected indicators of quality of care were examined. Similarly, no differences in survival emerged for the two
\end{abstract}

Istituto di Ricerche Farmacologiche "Mario Negri," Milan, Italy A LIBERATI, MD, senior investigator

$S$ MARSONI, MD, research associate

F PARAZZINI, MD, research fellow

G TOGNONI, MD, head, laboratory of clinical pharmacology

Prima Clinica Ostetrica e Ginecologica dell' Universita di Milano, Ospedale "S Gerardo" Monza, Milan

C MANGIONI, MD, head of department of obstetrics and gynaecology

L BRATINA, MD, head of pathology department

M REGALLO, MD, research fellow

Istituti Clinici di Perfezionamento Università di Milano

G CARINELLI, MD, head of pathology department

Centro Riferimento Oncologico-USL, 33081 Aviano

R TALAMINI, PHD, research fellow

Correspondence to: Dr Liberati. groups of hospitals. Overall results of the Italian series compared well with statistics of survival published by international centres for cancer, suggesting that when the yield of available treatments is limited both the process and outcome of care should be evaluated to obtain a reliable picture of quality of care. In the light of these results there are useful implications for planning future clinical trials and ways of caring.

\section{Introduction}

Although ovarian cancer is only the fourth most common cause of death from cancer in women, it is the major cause of death from a gynaecological malignancy in most developed countries. ${ }^{1}$ Despite claims of effective treatment in many reports of clinical trials, ${ }^{2}{ }^{3}$ statistics of survival do not indicate any substantial improvements in the management of the disease. ${ }^{45}$

The real yield of experimental treatments tested in randomised controlled trials is difficult to assess mainly because of the selection of patients and low quality of design and implementation of most of them, as has been recently documented. ${ }^{5}$ Poor compliance to key procedures, specifically understaging, is one factor causing the low impact of potentially effective treatments on cure and prolongation of survival. ${ }^{6}$

In 1979 in Italy we started a monitoring programme aimed at evaluating the process of care in patients with different malig- 